\title{
AVALIAÇÃO DE DIFERENTES MÉTODOS CROMATOGRÁFICOS NA DETERMINAC̄̃O DE ÁCIDOS GRAXOS EM SEMENTES DE MARACUJÁ (Passiflora edulis f. flavicarpa)
}

\author{
ERNANI S. SANT'ANNA * \\ REGINA COELI O. TÔRRES ** \\ ANNA CLAUDIA S. PORTO **
}

\begin{abstract}
Determinou-se a composição de ácidos graxos, por cromatografia em fase gasosa, do óleo da semente do maracujá amarelo (Passiflora edulis f. flavicarpa), em três diferentes tamanhos de frutos (tipo $1=12-15 \mathrm{~cm}$; tipo $2=7-10 \mathrm{~cm}$; tipo $3=$ 5-6 cm). O rendimento das sementes em relação ao peso dos frutos para os tipos 1,2 e $3(5,18 ; 5,83$ e $5,31 \%)$ e para a polpa dos tipos 1 e $3(12 ; 17$ e $12,67 \%$ ) não apresentou diferença entre os tamanhos analisados, com exceção do tipo 2 $(14,03 \%)$ para polpa que evidenciou maior rendimento. A composição em ácidos graxos do óleo da semente do maracujá amarelo, nos três diferentes tamanhos, mostrou predominância de ácidos graxos oléico e linoléico. O método mais adequado para a determinação da composição de ácidos graxos do óleo do maracujá foi o Cd 14c94/coluna SP 2340 da American Oil Chemists' Society.
\end{abstract}

\section{INTRODUÇÃO}

Mais de 400 espécies de maracujá são encontradas na América do Sul e do Norte, na África e na Ásia, sendo a espécie Passiflora edulis a mais comumente comercializada.

Na América do Sul, além do Brasil, o Peru, o Equador e a Colômbia produzem frutos de casca amarela da variedade flavicarpa, principalmente para o processamento, sendo estes os maiores mercados produtores de

* Professor Titular, Departamento de Ciência e Tecnologia de Alimentos, Universidade Federal de Santa Catarina (UFSC), Florianópolis, SC. (e-mail: ernanis@cca.ufsc.br).

** Alunas de Pós-Graduação, Departamento de Ciência e Tecnologia de Alimentos, UFSC, Florianópolis, SC. 
suco de maracujá. Nos Estados Unidos, a Califórnia e a Flórida cultivam o maracujá roxo e o Havaí produz o maracujá amarelo para concentrados. $\mathrm{Na}$ África e na Ásia a produção destina-se ao mercado local. A Nova Zelândia e a Malásia desempenham importante papel no mercado de concentrados (7).

O Brasil é o maior produtor mundial de maracujá, com produção anual de 172.290 toneladas (5). A Região Norte responde por 33\% da produção, a Nordeste participa com $46,9 \%$ e a Sudeste com cerca de $20 \%$ (6). A cultura do maracujazeiro no Brasil evoluiu muito rapidamente nas últimas décadas. Até o início da década de 70, o país não figurava sequer entre os principais produtores desta frutífera. Porém, antes mesmo do final da referida década, o Brasil passou a ser o maior produtor e o maior exportador de suco concentrado de maracujá $(6,12)$.

No Estado de Santa Catarina, nos últimos anos, a cultura do maracujá amarelo vem apresentando impacto no aspecto sócio-econômico, devido ao alto retorno financeiro para pequenos e médios produtores. Em 1991, a área plantada era de \pm 30 hectares, tendo sido estimado para 1997 área de 1000-1500 hectares. Com base nestes dados acredita-se numa superprodução e dentro deste quadro faz-se necessário a divulgação e transferência de novas tecnologias de processamento. Entretanto, especial atenção deve ser dada para a utilização econômica dos subprodutos do processamento do maracujá, uma vez que o volume deste resíduo industrial constitui-se em sério problema ambiental. Como subprodutos da industrialização da polpa de maracujá aparecem as cascas e as sementes, que representam aproximadamente 50 e 13\%, respectivamente, da matéria-prima. As sementes do maracujá contêm $10 \%$ de proteína e $20 \%$ de óleo comestível, o qual é considerado melhor do que o óleo de algodão, em relação ao valor alimentar e digestibilidade (7).

MEDINA \& TURATTI (1994) descreveram o óleo obtido a partir da semente de maracujá como sendo amarelo, de sabor agradável e odor suave, podendo ser usado para fins cosméticos, industriais e na alimentação animal e humana.

GAYDOU \& RAMANOELINA (1983) pesquisando o perfil de ácidos graxos e esteróis do óleo da semente de maracujá, bem como seu provável uso na alimentação humana, avaliaram a qualidade dietética do óleo em ratos albinos. Como não foi observada nenhuma modificação no metabolismo afirmaram que este óleo pode ser usado para fins comestíveis.

MELO \& ANDRADE (1996) também avaliaram o óleo da semente de maracujá para fins alimentícios. Mediante testes sensoriais com frituras e salada de verduras comprovaram qualidade superior em relação a alguns óleos comestíveis (soja, algodão e girassol) e recomendaram o emprego do óleo da semente de maracujá amarelo na alimentação humana. 
O presente trabalho teve por objetivo determinar a composição em ácidos graxos da semente do maracujá amarelo (Passiflora edulis f. flavicarpa), de três diferentes tamanhos, utilizando diferentes metodologias cromatográficas.

\section{MATERIAL E MÉTODOS}

\subsection{MATERIAL}

Foram usadas sementes de maracujá amarelo (Passiflora edulis $\mathrm{f}$. flavicarpa), provenientes da Cooperativa Agropecuária de Jacinto Machado - Jacinto Machado (SC), em três diferentes tamanhos de frutos, ou seja, tipo 1 (12-15 cm de diâmetro), tipo 2 (7-10 cm de diâmetro) e tipo 3 (5-6 $\mathrm{cm}$ de diâmetro), sendo cada lote com 20 unidades.

As sementes foram lavadas para remoção da polpa e posteriormente secas em estufa com circulação de ar (FABBE, modelo 170) a $45^{\circ} \mathrm{C}$ por 24 horas. Posteriormente foram trituradas (granulometria de 20 mesh) e 0 óleo extraído com hexano e evaporação do solvente. O óleo obtido foi acondicionado em vidros e estocado em temperatura ambiente.

\subsection{MÉTODOS}

A determinação da composição em ácidos graxos foi efetuada em cromatógrafo a gás HP 5890, Integrador 3393 A. Os métodos da American Oil Chemists' Society (AOCS) Cd 14c-94 (1994) em coluna SP 2340 - 60 m x 0,25 mm ID x 0,20 $\mu \mathrm{m}$; AOCS Cd 14c-94 (1994) em coluna Carbowax $20 \mathrm{M}(50 \mathrm{~m} \times 0,20 \mathrm{~mm} \times 0,20 \mu \mathrm{m})$; AOCS Cd 1f-96 (1994) em coluna Carbowax 20M (50 $\mathrm{m} \times 0,20 \mathrm{~mm} \times 0,20 \mu \mathrm{m})$ e o método descrito por CORRÊA et al. (1994) em coluna Carbowax 20M foram utilizados para as amostras tipo 1 e o AOCS cd 14c-94 (1) para as amostras tipo 2 e 3.

\section{- Condições Cromatográficas}

No método AOCS Cd 14c-94/Coluna SP 2340 empregou-se temperatura do detector de $270{ }^{\circ} \mathrm{C}$ e do injetor de $250{ }^{\circ} \mathrm{C}$, com a seguinte programação: temperatura inicial $=165^{\circ} \mathrm{C}(15 \mathrm{~min})$ e incremento de $5{ }^{\circ} \mathrm{C} / \mathrm{min}$ até temperatura final $=200{ }^{\circ} \mathrm{C}(6 \mathrm{~min})$. Gás de arraste hidrogênio ultra-puro, vazão $1,2 \mathrm{~mL} / \mathrm{min}$ a 20 psi.

O método AOCS Cd 14c-94/Coluna Carbowax 20M prevê temperatura do detector de $270{ }^{\circ} \mathrm{C}$ e a do injetor de $250{ }^{\circ} \mathrm{C}$, com programação conforme segue: temperatura inicial $=165^{\circ} \mathrm{C}(15 \mathrm{~min})$ e incremento de $5^{\circ} \mathrm{C} / \mathrm{min}$ até 
temperatura final $=200{ }^{\circ} \mathrm{C}(6 \mathrm{~min})$. Gás de arraste hidrogênio ultra-puro, vazão $1,2 \mathrm{~mL} / \mathrm{min}$ a 30 psi.

No método AOCS Cd 1f-96/Coluna Carbowax 20M são empregadas as seguintes condições: temperatura do detector e injetor de $250{ }^{\circ} \mathrm{C}$, temperatura da coluna em processo isotérmico de $192{ }^{\circ} \mathrm{C}$, gás de arraste hidrogênio ultra-puro, vazão de $1,2 \mathrm{~mL} / \mathrm{min}$ a 30 psi.

Segundo a metodologia utilizada por CORRÊA et al. (1994) as condições de análise são: temperatura do detector de $220^{\circ} \mathrm{C}$ e do injetor de $110^{\circ} \mathrm{C}$. Temperatura inicial de $110^{\circ} \mathrm{C}$, durante 1 minuto seguida de aquecimento de $10^{\circ} \mathrm{C} / \mathrm{min}$ até $170^{\circ} \mathrm{C}(2 \mathrm{~min})$, aquecimento de $1,5^{\circ} \mathrm{C} / \mathrm{min}$ até $173^{\circ} \mathrm{C} \mathrm{e}$ aquecimento de $1{ }^{\circ} \mathrm{C} / \mathrm{min}$ até $180{ }^{\circ} \mathrm{C}(7 \mathrm{~min})$. Gás de arraste $\mathrm{He}$ $(1,89 \mathrm{~mL} / \mathrm{min}$ a $30 \mathrm{psi})$.

\section{- Preparação dos ésteres metílicos}

Pesaram-se $4 \mathrm{~g}$ da fase oleosa em balão de destilação de $125 \mathrm{~mL}$. Após adição de $5 \mathrm{~mL}$ de solução alcoólica de hidróxido de potássio $0,5 \mathrm{~N}$ colocou-se o balão em refluxo por 3 minutos. Adicionaram-se ao balão ainda quente, $15 \mathrm{~mL}$ da solução cloreto de amônio/ácido sulfúrico em metanol (16 g de cloreto de amônio, $480 \mathrm{~mL}$ de metanol e $24 \mathrm{~mL}$ de ácido sulfúrico concentrado) e colocou-se o balão novamente em refluxo por três minutos. Após a amostra ter esfriado foi adicionado $10 \mathrm{~mL}$ de heptano. A mistura obtida foi transferida para funil de separação de $60 \mathrm{~mL}$, agitandose o funil vigorosamente por 15 segundos. A fase foi extraída com heptano e filtrada através de papel filtro com $\pm 3 \mathrm{~g}$ de sulfato de sódio anidro. A fase do heptano foi transferida para frasco de $5 \mathrm{~mL}$ com tampa e injetado $1 \mu \mathrm{L}$ no cromatógrafo (HARTMAN \& LAGO, 1973).

\section{RESULTADOS E DISCUSSÃo}

O rendimento (média $=20$ ) das sementes em relação ao peso bruto dos frutos não apresentou diferença entre os tipos 1, 2 e 3 (tamanho do fruto), com valores de 5,$18 ; 5,83$ e 5,31\%, respectivamente.

Para as sementes em relação à polpa, o tipo $2(14,03 \%)$ obteve o maior rendimento, enquanto que os tipos $1(12,17 \%)$ e $3(12,67)$ foram semelhantes entre si.

$\mathrm{Na}$ amostra tipo 1, o método que melhor separou os ésteres metílicos foi o AOCS Cd 14c-94/Coluna SP 2340. Os métodos AOCS Cd 14c-94, AOCS Cd 1f-96 e o método descrito por CORRÊA et al. (2), todos utilizando 
colunas Carbowax 20M, não apresentaram separação definida e/ou reprodução dos picos característicos (Figura 1).

FIGURA 1 - CROMATOGRAMAS DO ÓLEO DA SEMENTE DE MARACUJÁ AMARELO (Passiflora edulis $f$. flavicarpa) DA AMOSTRA TIPO 1 (12 A $15 \mathrm{~cm}$ DE DIÂMETRO) DETERMINADOS PELOS MÉTODOS: AOCS Cd 1F-96 (A); AOCS Cd 14C-94 (B); AOCS Cd 14-94, EM COLUNA CARBOVAX $20 \mathrm{M}$

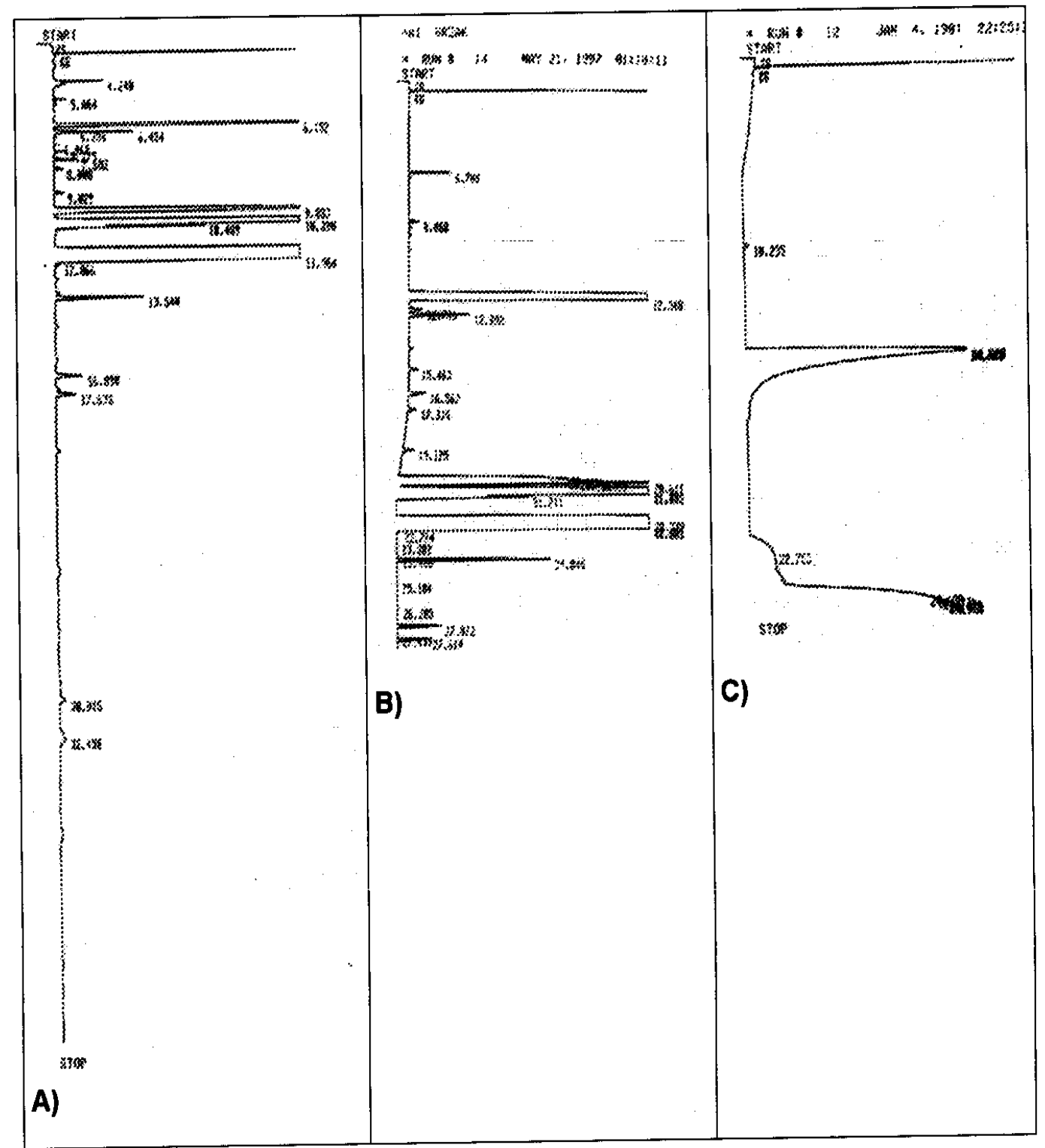


A análise cromatográfica das amostras tipo 2 e 3 foram efetuadas apenas através do método AOCS Cd 14c-94/coluna SP 2340 por ter sido considerado o método mais satisfatório (Figura 2).

FIGURA 2 - CROMATOGRAMAS DO ÓLEO DA SEMENTE DE MARACUJÁ AMARELO (Passiflora edulis $f$. flavicarpa) NAS AMOSTRAS TIPO 1 (12-15 cm DE DIÂMETRO); TIPO 2 (7-10 cm DE DIÂMETRO) E TIPO $3 \quad(5-6 \mathrm{~cm}$ DE DIÂMETRO) PELO MÉTODO AOCS Cd 14c-94 EM COLUNA SP 2340

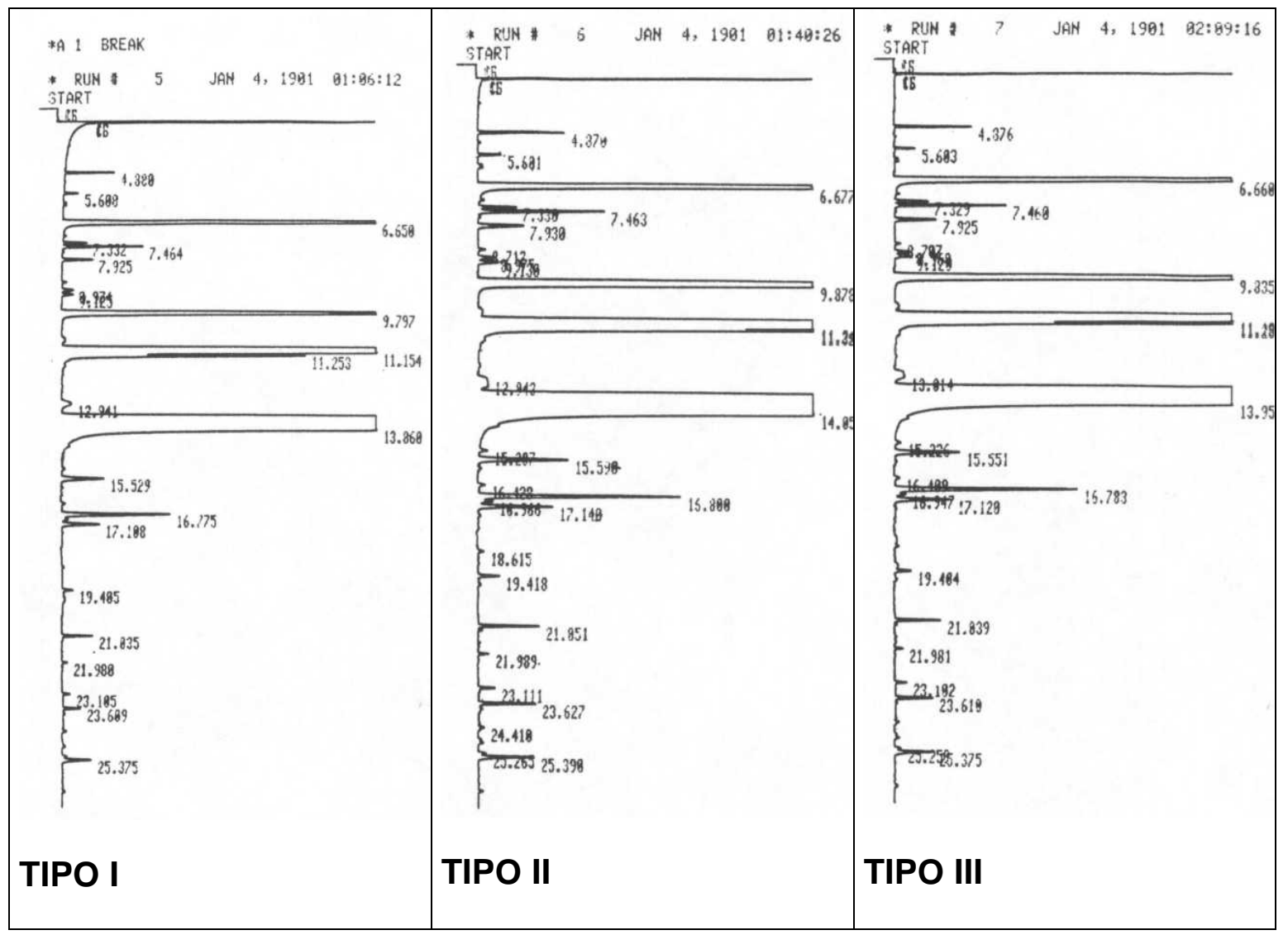

A composição em ácidos graxos do óleo de semente de maracujá (Tabelas 1 e 2) evidenciou predominância de ácidos graxos insaturados (oléico e linoléico).

PONTES et al. (1989) em estudos para o aproveitamento dos subprodutos do maracujá, avaliando o teor de ácidos graxos das sementes, encontraram os seguintes valores: ácido palmítico $11,0 \%$, ácido esteárico (C18) 2,80\%, ácido oléico 17,5\% e linoléico 68,70\%. 


\section{TABELA 1 - COMPOSIÇÃO EM ÁCIDO GRAXO (\%) DO ÓLEO DA SEMENTE DE MARACUJÁ AMARELO (Passiflora edulis $\mathrm{f}$. flavicarpa) DA AMOSTRA TIPO $1 \quad(12-15 \quad \mathrm{~cm}$ DE DIÂMETRO), DETERMINADA POR TRÊS MÉTODOS}

\begin{tabular}{|c|c|c|c|}
\hline \multirow{3}{*}{ ÁCIDOS GRAXOS } & \multicolumn{3}{|c|}{ AMOSTRA TIPO 1} \\
\hline & AOCS Cd 1f-96 & AOCS Cd 14c-94 & AOCS Cd 14-94 \\
\hline & Carbowax 20M & SP 2340 & Carbowax 20M \\
\hline $\mathrm{C} 14: 0$ & 0,10 & 0,07 & 0,07 \\
\hline C16:0 & 10,73 & 10,94 & 10,79 \\
\hline C16:1,17 & 0,42 & 0,37 & 0,42 \\
\hline C18:0 & 2,77 & 2,75 & 2,76 \\
\hline C18:1c & 15,00 & 15,11 & 14,98 \\
\hline C18:1t & - & - & - \\
\hline $\mathrm{C} 18: 2 \mathrm{c}$ & 70,01 & 69,67 & 70,06 \\
\hline $\mathrm{C} 18: 2 \mathrm{t}$ & - & 0,09 & - \\
\hline $\mathrm{C} 18: 3 \mathrm{c}$ & 0,41 & 0,41 & 0,41 \\
\hline $\mathrm{C} 18: 3 \mathrm{t}$ & - & - & 0,02 \\
\hline C20:0 & 0,17 & 0,17 & 0,17 \\
\hline $\mathrm{C} 20: 1$ & 0,13 & 0,13 & 0,13 \\
\hline $\mathrm{C} 22: 0$ & 0,07 & 0,07 & - \\
\hline $\mathrm{C} 22: 1$ & - & 0,01 & - \\
\hline $\mathrm{C} 24: 0$ & - & 0,09 & - \\
\hline Total Trans & - & 0,09 & 0,02 \\
\hline Ác. Saturados & 13,84 & 14,09 & 13,79 \\
\hline Ác. Monoinsaturados & 15,55 & 15,62 & 15,53 \\
\hline Ác. Polinsaturados & 70,42 & 70,08 & 70,47 \\
\hline
\end{tabular}

(-) não detectado.

PRASAD (1980), analisando óleo de sementes de maracujá, obteve para os ácidos palmítico $11,0 \%$, esteárico $2,0 \%$, oléico $14,0 \%$, linoléico $73,5 \%$ e para linolênico e araquídico traços.

Os percentuais encontrados neste trabalho, para as amostras tipo 1, 2 e 3, mostram valores de ácido palmítico semelhantes aos encontrados por PRASAD (1980) e PONTES et al. (1989). 
Os teores de ácido linoléico e esteárico encontrados foram semelhantes aos obtidos por PONTES et al. (1989). Porém, quando comparados aos valores verificados por PRASAD (1980) apresentaram-se menores para 0 ácido linoléico e maiores para o ácido esteárico.

O ácido oléico apresentou valores inferiores nos três tipos de amostras analisadas em relação aos valores reportados por PONTES et al. (1989) e semelhantes aos valores obtidos por PRASAD (1980).

TABELA 2 - COMPOSIÇÃO EM ÁCIDO GRAXO (\%) DO ÓLEO DA SEMENTE DE MARACUJÁ AMARELO (Passiflora edulis $\mathrm{f}$. flavicarpa) DAS AMOSTRAS TIPO 2 E 3 (7-10 E 5-6 cm DE DIÂMETRO), PELO MÉTODO AOCS CD 14C-94/COLUNA SP 2340

\begin{tabular}{l|c|c}
\hline ÁCIDOS GRAXOS & AMOSTRA TIPO 2 & AMOSTRA TIPO 3 \\
\hline $\mathrm{C} 14: 0$ & 0,08 & 0,07 \\
\hline $\mathrm{C} 16: 0$ & 11,24 & 10,58 \\
\hline $\mathrm{C} 16: 1,17$ & 0,38 & 0,38 \\
\hline $\mathrm{C} 18: 0$ & 3,09 & 3,04 \\
\hline $\mathrm{C} 18: 1 \mathrm{c}$ & 15,35 & 15,30 \\
\hline $\mathrm{C} 18: 1 \mathrm{t}$ & - & - \\
\hline $\mathrm{C} 18: 2 \mathrm{c}$ & 68,68 & 69,39 \\
\hline $\mathrm{C} 18: 2 \mathrm{t}$ & 0,03 & 0,08 \\
\hline $\mathrm{C} 18: 3 \mathrm{c}$ & 0,39 & 0,46 \\
\hline $\mathrm{C} 18: 3 \mathrm{t}$ & 0,02 & 0,01 \\
\hline $\mathrm{C} 20: 0$ & 0,18 & 0,18 \\
\hline $\mathrm{C} 20: 1$ & 0,13 & 0,13 \\
\hline $\mathrm{C} 22: 0$ & 0,08 & 0,07 \\
\hline $\mathrm{C} 22: 1$ & 0,01 & 0,01 \\
\hline $\mathrm{C} 24: 0$ & 0,09 & 0,08 \\
\hline Total Trans & 0,05 & 0,09 \\
\hline Ác. Saturados & 14,76 & 14,02 \\
\hline Ác. Monoinsaturados & 15,87 & 15,82 \\
\hline Ác. Polinsaturados & 69,07 & 69,85 \\
\hline
\end{tabular}

(-) não detectado.

\section{CONCLUSÃo}

A metodologia mais adequada para a determinação da composição de ácidos graxos foi AOCS Cd 14c-94/coluna SP2340, por apresentar a melhor resolução cromatográfica. 
Utilizando o método AOCS Cd 14c-94/coluna Carbowax 20M os resultados foram semelhantes ao acima citado, não ocorrendo separação cromatográfica entre os picos C16 e C18 nem reprodução dos picos característicos de C22 e C24.

Com o método AOCS Cd 1f-96/coluna Carbowax 20M os resultados também foram semelhantes, não havendo reprodução do pico característico de C24.

O método de CORRÊA et al. (1994) empregando coluna Carbowax 20M não apresentou separação satisfatória dos ácidos graxos de óleo de semente de maracujá amarelo.

\section{Abstract}

Fatty acids composition was determined in three different sizes (type $1=12-15 \mathrm{~cm}$; type $2=7-10 \mathrm{~cm}$; type $3=5-6 \mathrm{~cm}$ ) of yellow passion fruit (Passiflora edulis f. flavicarpa) oil using gas chromatography. The seed yield in terms of fruit weight to types 1,2 and $3(5,18 ; 5,83$ and $5,31 \%)$ and fruit pulp to types 1 and $3(12,17$ and 12,67\%) didn't present differences between the sizes analyzed with the exception of fruit pulp type $2(14,03 \%)$ that showed the highest yield. The fatty acids composition of yellow passion fruit oil, in three different sizes, showed a predominance of oleic and linoleic acids. The more suitable methodology for passion fruit oil fatty acids determination was AOCS Cd 14c-94/column SP 2340.

\section{REFERÊNCIAS}

1 AOCS. American Oil Chemists' Society. Official methods and recommended practices of the AOCS. $4^{\text {th }}$ ed. Champaign, 1994. (Additions and revisions 1996-1997).

2 CORRÊA, N.C.F.; MEIRELES, M.A.A.; FRANÇA, L.F.; ARAÚJO, M.E. et al. Extração de óleo da semente de maracujá (Passiflora edulis) com $\mathrm{CO}_{2}$ supercrítico. Ciência e Tecnologia de Alimentos, v. 14 (Supl.), p. 29-37, dez. 1994.

3 GAYDOU, E.M.; RAMANOELINA, A.R.P. Valorisation des sousproduits de l'industrie du jus des fruits de grenadille: composition en acides gras et en stérols de l'huile des graines. Fruits, v. 38, n. 10, p. 1-10, 1983.

4 HARTMAN, L.; LAGO, R.C.A. Rapid preparations of fatty acid methyl esters from lipids. Laboratory Practice, v. 22, n. 8, p. 475-476, 1973. 
5 IBGE. INSTITUTO BRASILEIRO DE GEOGRAFIA E ESTATÍSTICA. Anuário estatístico do Brasil. Rio de Janeiro, 1990. v. 50, p. 3.33.25. (Secção 3 - Aspectos das Atividades Agropecuárias e Extração Vegetal).

6 LIMA, A.A. A pesquisa no Brasil com a cultura do maracujá. Cruz das Almas: EMBRAPA-CNPMF, 1994. 14 p. (EMBRAPA-CNPMF. Documentos, 55).

7 MANICA, I. Fruticultura tropical: maracujá. São Paulo: Agronômica Ceres, 1981. $160 \mathrm{p}$.

8 MEDINA, J.C.; TURATTI, J.M. Processamento: produtos, caracterização e utilização - subprodutos. In: MARACUJÁ: cultura, matéria-prima, processamento e aspectos econômicos. Campinas: ITAL, 1994.

9 MELO, H. C.; ANDRADE, A.R.D. Caracterização do óleo da semente de maracujá para fins alimentícios. In: CONGRESSO BRASILEIRO DE CIÊNCIA E TECNOLOGIA DE ALIMENTOS, 15., 1996. Anais... Poços de Caldas, 1996.

10 PONTES, M.A.N. et al. Estudos dos subprodutos do maracujá (Passiflora edulis f. flavicarpa Deg.): III. Obtenção do óleo e da torta. Boletim do CEPPA, v. 7, n. 1, p. 23-321, 1989

11 PRASAD, J. Pectin and oil passion fruit waste. Fiji Agricultural Journal, v. 42, p. 45-48, 1980.

12 RUGGIERO, C. et al. Maracujá para exportação: aspectos técnicos de produção. Brasília: EMBRAPA, Ministério da Agricultura e Abastecimento e Reforma Agrária. Secretaria do Desenvolvimento Rural. Programa de Apoio à Produção e Exportação de Frutas, Hortaliças, Flores e Plantas Ornamentais, 1996. 64 p. 